\section{Threat or Blessing?}

Nuclear Power and the Public. Edited by Harry Foreman. Pp. xviii +273 . (University of Minnesota: Minneapolis ; Oxford University: London, March 1971.) $£ 4.25$.

THIs book consists of a series of papers presented at a conference held at the University of Minnesota in 1969. The motivation for this conference lay in the public concern felt about the possible effects on the environment of a high megawattage nuclear power plant being built 40 miles up the Mississippi from the twin cities of Minneapolis and St Paul. Prior to this, the issues at stake in allowing the Northern Power Company to proceed with building the nuclear plant had aroused widespread concern within the United States and the aims were to present the facts about environmental pollution arising from nuclear power plants for the benefit of all. The symposium brought together scientists working in the field of radiation effects together with experts and recognized authorities in all fields relating to the problem of generating power from nuclear reactors.

It is a fact that the consumption of electric power in the United States has doubled every decade since 1940 . The long term predictions are for this rate of power consumption to continue at an ever increasing rate. It had become apparent that some alternative to fossil fuels as a source of power would be needed, and the answer seemed to lie in nuclear power. The ever increasing concern about maintaining the state of the environment, however, has led people to question whether this form of power generation is creating a larger problem than it is solving. The conference proceedings present the facts but by-and large the reader has to make up his own mind whether or not the advantages of nuclear power outweigh the disadvantages.

One of the most striking aspects of the proceedings is the lack of agreement between the two factions that are seen to emerge. The authorities concerned with the design, building and planning of nuclear power plants continuously make the point that all nuclear power plants in the United States more than conform to Grovernment regulations concerning the pollution of the environment with radioactive and other waste. The conservationists argue, convincingly, it must be said at times, that some of the regulations and maximum permissible levels set down are far from adequate to protect the public.

The final conference papers deal with the benefits and risks of nuclear power. They are delivered by proponents of both sides of the argument, Dr Barry Commoner, professor of plant physio- logy at Washington University, St Louis, and James T. Ramsey, a commissioner of the US Atomic Energy Commission. Commoner, who introduces the concept of a benefit/risk ratio, points out that the standards of safety set by the Federal Radiation Council (FRC) are based on the conclusion that the risks of radiation exposure are proportional to the dose of radiation received. Therefore as there is no intrinsically safe level, all standards set by the FRC require judgment of how large a risk should be taken by the population in return for the value gained from the activity that caused the exposure. Ramsey makes the point that the benefits of nuclear power are great in terms of low cost and conservation of resources and also, compared with fossil fuel plants, beneficial in conservation of the environment. On what common grounds do the proponents meet? There is indeed some measure of agreement; both feel that it is up to the public to study the facts and make judgments based on them. Ramsey also feels that the scientific community should play a more important role in assisting the public in this regard.

All the papers presented in the book contain some facts and figures that are directly applicable to the problem of environmental pollution. The conservationists put forward their case with conviction but unfortunately seem to be operating in a vacuum with no relation to the power needs of the United States. The representatives of the governmental agencies seem to shield behind nationally and internationally recognized radiation standards. There is obviously need for cooperation on inquiries into the viability of radiation standards.

For anyone with even a passing interest in the subject the book is well worth reading. On the basis of the facts found within the thirteen papers, a reasoned judgment can and should be made on whether the present standards of safety set when building nuclear power stations are adequate, or whether a new and more stringent set of standards are required that would in all probability increase the cost of power generation. ALUN JONES

\section{Migraine Described}

Migraine: The Evolution of a Common Disorder. By Oliver W. Sacks. Pp. 298. (Faber and Faber: London, January 1971.) $£ 2.50$.

THE mechanism and underlying causes of migraine remain elusive, despite a growing volume of research which has already produced some tantalizing clues. Indeed, a comprehensive theory of causation is still lacking; one which would account for all the clinical manifestations of this widespread and disagreeable disorder, as well as for the precipitation of attacks by dietary, hormonal, emotional, visual and other stimuli-or apparently by none at all.

Dr Sacks aims to fill this gap, and in his book gives his personal construction of the psycho-biological substructure of migraine. The early chapters describe the various clinical forms and presentations of migraine (with many illustrative case histories) and discuss these in the light of the author's particular interests. The core of the argument, however, lies in the section on "The Basis of Migraine". Sacks interprets the observed and experienced phenomena of the migraine attack as being essentially manifestations of a slow excitation-inhibition-excitation cycle of electrical activity arising within the brain; "a form of centrencephalic seizure, the activity of which is projected rostrally on the cerebral hemispheres and peripherally via the ramifications of the autonomic nervous system" (p. 212), thus accounting for the variety of symptomatology. The circumstances which provoke the attack, together with certain of the neurological prodromata, are seen as the initial excitation. The inhibitory phase occupies the principal part of the attack, manifested by withdrawal of the patient into his suffering and eventually into sleep; an accompanying excess of parasympathetic activity being responsible for vomiting and for the vasodilatation which is the immediate cause of the headache and which may be localized. Finally, the sense of wellbeing accompanying recovery is seen as the next phase of excitation.

The author points out that a biological basis for such a reaction does exist in the possibility of response to threat by withdrawal and conservation, rather than by fight and flight. These two responses seem to be innate in man as well as in animals. Migraine attacks are classified as paroxysmal-due primarily to neuronal instability with little external provocation, circumstantialresulting from excess of external or internal physical stimulation-and habitual-in which the stress is some emotion, experienced as dangerous, and in which the migraine attack may also have a symbolic content.

This makes an agreeably comprehensive theory, but is Sacks right? It is difficult to know, for the evidence which he presents in support of his views is scanty. This evidence rests entirely on his interpretation of the migraine attack as the result of waxing and waning of excitation of brain structures, and on the importance which he places on the significance and nature of those rare clinical states, involving particularly the aura, which lie on the borders of both 